\title{
frrabahonecessário
}

issn: 1808 - 799x

ano 8 - número 11 - 2010

\section{ARTIGO \\ POLÍTICA DE FORMAÇÃO DO TRABALHADOR DOCENTE: O QUE HÁ DE NOVO?}

\author{
Maria Inês Bomfim - mariaines.uff@gmail.com
}

\section{Resumo}

O artigo pretende oferecer subsídios ao debate sobre a política de formação docente do Governo Federal estabelecida, em janeiro de 2009, pelo Decreto ${ }^{\circ}$ 6755. Buscando superar as análises que situam a formação do trabalhador docente em separado das relações sociais de produção, destacamos o protagonismo dos organismos internacionais na definição das estratégias do setor, sustentando que a atual política de formação do trabalhador docente reitera soluções restritas adotadas anteriormente, de forma compatível com a lógica do capital que se amplia para a área de serviços.

\section{Palavras-chave:}

trabalho docente - formação docente - educação básica

\section{Introdução}

Em janeiro de 2009, o Governo Lula da Silva lançou, por decreto, a atual política de formação docente, destinando às ações previstas um expressivo volume de recursos financeiros, com a promessa de valorização do magistério da educação básica pública. Uma política de formação poderia romper com a lógica do capital no interesse dos trabalhadores docentes?

Defendendo que o trabalho e a formação docente são determinados historicamente pelo modo de produção capitalista, procuramos, neste artigo, superar as concepções que os situam em separado das relações sociais de

\footnotetext{
1 Doutora em Educação. Professora da Faculdade de Educação da Universidade Federal Fluminense- UFF.
} 
issn: 1808 - 799x

ano 8 - número 11 - 2010

produção. Tal compreensão nos levou a analisar a atual política de formação à luz daquilo que tem caracterizado a expansão capitalista no Brasil, isto é, o desenvolvimento dependente, desigual e associado ao grande capital, instrumento de viabilização da inserção subalterna do país na divisão internacional do trabalho, destinando à grande maioria dos brasileiros formação escolar para o trabalho simples e conformação à lógica capitalista.

Organizamos o presente artigo em duas seções. Na primeira, O modo de produção capitalista e o trabalho de ensinar, tratamos do processo de mercantilização vivido pelos trabalhadores docentes, expressão do atual momento do capitalismo. Na segunda, Políticas de formação do trabalhador docente da educação básica: o que há de novo?, observamos os limites da formação docente inicial e continuada proposta pelo Governo Federal.

\section{O modo de produção capitalista e o trabalho de ensinar}

A história da produção capitalista é a história da busca de ampliação da taxa de mais-valia pelo capital. Sob o predomínio da subsunção real, não só a vida produtiva, mas, também, a vida social gira em torno da produção de mais- valia, para o quê as ideologias sobre o mercado e sobre o capitalismo como processo natural e insuperável são fundamentais. "A força do conceito de mercado está, pois, em sua estrutura 'totalizante', como se diz hoje em dia, ou seja, em sua capacidade de nos oferecer um modelo de totalidade social" (JAMESON, 2002 p. 280).

Nessa perspectiva, o movimento de preservação e auto-expansão do capital não poderia deixar de fora os serviços. Para a valorização do capital, todas as atividades precisam estar aptas a contribuir à sua preservação. Ao incorporar essa lógica, os serviços públicos são submetidos aos mesmos critérios de eficiência capitalista, promovendo nas atividades mais altamente humanas uma verdadeira "hemorragia de sentido" (Sève,1999).

No Brasil, os últimos anos da década de 1990 voltaram-se à complementação de ajustes iniciados em anos anteriores para o enfrentamento da crise estrutural capitalista e à afirmação conservadora de um "novo" pensamento 
pedagógico que vem se atualizando em torno das mesmas bases. As políticas do período trouxeram uma nova visão do que é público, desvinculado do estatal, na qual as organizações civis e o livre mercado, em sintonia com interesses de frações da burguesia nacional e do capital financeiro internacional, são considerados mais eficientes do que o Estado.

No plano ideológico acentuou-se, primeiramente, a idéia de que "um admirável mundo novo" emergia com a globalização e com a revolução tecnológica, sendo este mundo disponível para todos. Esse mundo novo, no qual o conhecimento seria o principal motor de crescimento econômico, atualizando, com novas roupagens, a velha Teoria do Capital Humano, exigiria uma nova educação, um outro professor e práticas pedagógicas ajustáveis à flexibilidade requerida pelo mercado. O professor da escola básica pública, entretanto, não estaria preparado para este novo mundo. Suas práticas pedagógicas, consideradas ultrapassadas e pouco eficazes, deveriam ser substituídas pelas chamadas "boas práticas".

Curvar o trabalhador docente e controlar o seu trabalho passaram a ser condições essenciais para melhores resultados na educação. O Banco Mundial, o BID, a UNESCO e, também, o PREAL- Programa de Promoção da Reforma Educativa da América Latina e Caribe assumiram a defesa, em conjunto ou separadamente, de uma maior flexibilidade das leis e das normas de contratação docente, incentivos salariais seletivos, recompensas não-monetárias, ampliação do tempo exigido para aposentadoria, maior ênfase na formação de competências e habilidades do que nos conteúdos informativos e premiação de escolas e professores pelos seus resultados.

Os professores, comparados a não-docentes, teriam, conforme a avaliação desses organismos, além de salário bruto por hora-trabalhada superior ao de outros profissionais com o mesmo nível de escolaridade, especialmente o salário inicial, estabilidade e aposentadoria precoce (PREAL,2007). Não caberia aos "governantes conscientes" propor aumentos significativos de remuneração para a categoria, justifica o PREAL. Mesmo considerando as resistências políticas e institucionais às mudanças nos estatutos do magistério, "os governantes não podem negar-se a considerá-los" (PREAL, 2007). Na verdade, o cerco aos 
issn: 1808 - 799x

ano 8 - número 11 - 2010

professores das redes públicas transformou-se numa rentável estratégia, como é o caso, por exemplo, do "Método Stallings de Observação da Sala de Aula", oferecido, pelo Banco Mundial, aos estados do Rio de Janeiro, Minas Gerais, São Paulo e, também, ao município do Rio de Janeiro. ${ }^{2}$

Nessa cena política, as modalidades de expropriação dos trabalhadores docentes das redes públicas se multiplicaram, em virtude do crescimento do número de professores contratados sucessivamente de forma temporária e dos efetivos com dupla jornada, da manutenção dos baixos salários e da precarização da formação inicial. Os efeitos para a vida dos professores não foram poucos, devendo-se atentar para o provável agravamento desse quadro, em conseqüência dos desdobramentos da última crise econômica, definida por Francisco Oliveira (2009) como a "crise da globalização do capital".

O discurso da valorização docente, da busca de consenso em torno de uma necessária participação do professor para o sucesso de reformas e planos implementados a partir dos anos 1990 vem, por tudo isso, escondendo o lugar subordinado a ser assumido, pelo professor. As tentativas de curvar os docentes das redes públicas, expropriando ou flexibilizando direitos conquistados anteriormente e, ainda, ampliando a sua responsabilidade pela aprendizagem dos alunos tendo a "produtividade" como meta são bons exemplos do processo de mercantilização vivido pela categoria, característico da subsunção real ao capital.

\section{Políticas de formação do trabalhador docente: o que há de novo?}

O enfraquecimento do trabalhador docente, nas dimensões material e simbólica, tem muitas faces que não podem ser tomadas de forma independente da realidade que as engendram. A formação inicial desqualificada e a ausência de condições adequadas de trabalho para os professores da educação básica, incluindo a formação continuada, são processos vivenciados de forma combinada há décadas no Brasil e agravados na atual conjuntura.

\footnotetext{
2 O "método" busca saber quais reformas, programas e incentivos funcionam melhor. Embora seja escassa a documentação do Banco a respeito, depreendemos que são feitas 10 observações de cada classe por um observador que fotografa e preenche um questionário indicando que atividades estão sendo desenvolvidas pelo professor junto aos alunos. O observador pode ser da Secretaria, de firma contratada, ONGs etc. A finalidade é identificar que "insumos"(capacitação, premiações etc) funcionam melhor.
}

TrabalhoNecessário - www.uff.br/trabalhonecessario; Ano 8, Nº 11/2010. 
issn: 1808 - 799x

ano 8 - número 11 - 2010

A luta dos professores pela definição de uma política global de formação dos profissionais da educação e de valorização do magistério que contemple não apenas uma sólida formação inicial e continuada como condições de trabalho, salário e carreira dignas tem, no Brasil, mais de 30 anos. Em 1997, entretanto, na contra-mão desse movimento, o Decreto $n^{0} 2306$ definiu a organização acadêmica das IES, estabelecendo que essas instituições poderiam assumir formatos diferenciados, mantendo-se a exigência da pesquisa e extensão apenas nas universidades. ${ }^{3}$

Abriam-se, assim, por decreto, possibilidades de flexibilização da formação inicial docente, como a realizada pelos Institutos Superiores de Educação, reiteradas, posteriormente, pelo decreto $n^{\circ} 3276 / 99$, que dispõe sobre a formação em nível superior de professores para atuar na educação básica. De lá para cá, está em curso uma política de formação de professores que oferece diferentes oportunidades de formação aos futuros docentes, dependendo dos percursos anteriores na educação básica e das suas condições de classe, dissimulada sob a concepção de eqüidade (Freitas, 2007).

Em 2001, as Diretrizes Curriculares Nacionais para a Formação de Professores da Educação Básica, em nível superior, curso de licenciatura, de graduação plena, promulgadas pelo Conselho Nacional de Educação, alvo do Parecer $n^{\circ}$ 009/2001, atualizaram as políticas existentes, vinculando a educação à inserção do país no mundo globalizado. Dambiski (2006), estudando tendências no plano das políticas e da literatura especializada sobre a formação docente no período 2000-2007, observa a existência de 3 eixos articulados: o empobrecimento da noção de conhecimento, a excessiva valorização da epistemologia da prática e o enaltecimento das competências na formação docente.

Hoje, a formação inicial e continuada de professores está indicada em todos os documentos do Governo Lula da Silva que explicitam metas e

\footnotetext{
${ }^{3}$ O Decreto $n^{\circ} 3.276 / 1999$, que dispôs sobre a formação, em nível superior, de professores para atuar na educação básica, teve seu artigo $3^{\circ}$ modificado pelo Decreto $\mathrm{n}^{\circ} 3.554 / 2000$. Antes dessa alteração, determinava-se que a formação para atuar na Educação Infantil e nos anos iniciais do Ensino Fundamental, far-se-ia exclusivamente em cursos normais superiores. Depois de inúmeras discussões e manifestações contrárias, este termo foi alterado para preferencialmente, transformando o Curso Normal Superior em uma das alternativas para essa formação.
}

TrabalhoNecessário - www.uff.br/trabalhonecessario; Ano 8, No 11/2010. 


\section{frabalhonecessário}

issn: 1808 - 799x

ano 8 - número 11 - 2010

compromissos para a educação básica. Assim como as demais ações previstas no Plano de Desenvolvimento da Educação- PDE, a formação docente foi atrelada ao Índice de Desenvolvimento da Educação Básica (IDEB).

A política nacional de formação foi apresentada no Decreto $n^{\circ} 6755$, de 29 de janeiro de 2009, que disciplina, ainda, a atuação da Coordenação de Aperfeiçoamento de Pessoal de Nível Superior-CAPES no fomento a programas de formação inicial e continuada. A finalidade do decreto é "organizar, em regime de colaboração entre União, Estados, Distrito Federal e Municípios, a formação inicial e continuada dos profissionais do magistério das redes públicas de educação básica". A ênfase é a formação inicial ( $1^{\mathrm{a}}$ ou $2^{\mathrm{a}}$ licenciatura) dos professores, sem formação adequada, em exercício nas escolas públicas, sendo oferecidos cursos superiores, em 21 Unidades da Federação, por meio de 76 Instituições de Educação Superior- IES públicas, das quais 48 federais e 28 estaduais, com a colaboração de 14 universidades comunitárias. A meta nacional é a formação, até 2011 , de 330 mil professores, sendo $48 \%$ deles a distância, com investimento federal de 1,9 bilhão de reais.

A formação docente como compromisso público, embora vinculado a um ambicioso projeto de promoção da emancipação dos indivíduos e grupos sociais, cujas possibilidades efetivas de realização não estão na formação, mas em outro modelo de sociedade, é destacada como princípio. Igualmente, menciona-se a ênfase na articulação entre a teoria e a prática no processo de formação docente, fundada no domínio de conhecimentos científicos e didáticos, contemplando a indissociabilidade entre ensino, pesquisa e extensão, resgatando para a universidade o locus da formação inicial de professores.

Os princípios explicitam, ainda, velhos nós para os quais as medidas propostas no Decreto não parecem avançar significativamente: o regime de colaboração entre os entres federados e a articulação entre formação inicial e continuada, constatando a necessidade de políticas permanentes de estímulo à profissionalização, jornada única, progressão na carreira, formação continuada, dedicação exclusiva ao magistério, melhoria das condições de remuneração e garantia de condições dignas de trabalho. 
issn: 1808 - 799x

ano 8 - número 11 - 2010

O Decreto estabelece que a Política Nacional de Formação de Profissionais do Magistério da Educação Básica cumprirá seus objetivos por meio da criação dos Fóruns Estaduais Permanentes de Apoio à Formação Docente, em regime de colaboração entre a União, os Estados, o Distrito Federal e os Municípios, e por meio de ações e programas específicos do Ministério da Educação. Os Fóruns, presididos pelos Secretários Estaduais, parecem ter ação restrita, tanto em virtude da sua composição como da vinculação de suas possibilidades aos programas e ações já existentes no MEC. Embora o $\S 4^{\circ}$ do Artigo $4^{\circ}$ indique que "poderão integrar os fóruns representantes de outros órgãos, instituições ou entidades locais que solicitarem formalmente sua adesão", a composição básica definida, com apenas uma representação dos trabalhadores, via CNTE, sugere que o fórum funcione como um grupo de trabalho executor, em nível local, otimizando propostas formativas já existentes ou propostas "possíveis", dentro da ótica atual de formação. A esses fóruns, vale esclarecer, compete a realização do diagnóstico das necessidades de formação inicial e continuada, a indicação de cursos a serem oferecidos e a definição dos professores a serem atendidos, cabendo ao MEC a aprovação de ações presenciais e a distância, o que não parece, em si, garantir a autonomia dos entes federados ou assegurar um efetivo "regime de colaboração".

As necessidades de formação continuada de profissionais do magistério serão, conforme o Decreto, atendidas por atividades formativas e cursos de atualização, aperfeiçoamento, especialização, mestrado ou doutorado. Os cursos de atualização, aperfeiçoamento e especialização serão fomentados pela Coordenação de Aperfeiçoamento de Pessoal de Nível Superior-CAPES, ofertados por instituições públicas de educação superior, criando-se uma espécie de cardápio de cursos. A CAPES, instituição que assume, pelo Decreto, os rumos da formação docente, incentivará, ainda, a formação de profissionais do magistério para atuar na educação básica, mediante fomento a programas de iniciação à docência e concessão de bolsas a estudantes matriculados em cursos de licenciatura de graduação plena nas instituições de educação superior, o que inclui a iniciativa privada. O Decreto não esclarece, entretanto, que peso terá essa participação no conjunto das ações formativas. Da mesma forma, restringe a 
issn: 1808 - 799x

ano 8 - número 11 - 2010

questão da valorização do trabalhador docente ao direito à formação estimulada por uma bolsa.

O Artigo 11, por sua vez, sugere que, dentro do próprio MEC, existam concepções diferentes de formação docente em disputa. De forma incoerente com os princípios elencados e sem explicitar os vínculos com os planos estaduais, indica-se que a CAPES fomentará, ainda, um conjunto de ações pulverizadas, isto é, projetos pedagógicos que visem a promover novos desenhos curriculares ou percursos formativos destinados aos profissionais do magistério; projetos pedagógicos que visem a promover desenhos curriculares próprios à formação de profissionais do magistério para atendimento da educação do campo, dos povos indígenas e de comunidades remanescentes de quilombos; oferta emergencial de cursos de licenciaturas e de cursos ou programas especiais dirigidos aos docentes em exercício há pelo menos três anos na rede pública; projetos de revisão da estrutura acadêmica e curricular dos cursos de licenciatura; pesquisas destinadas ao mapeamento, aprofundamento e consolidação dos estudos sobre perfil, demanda e processos de formação de profissionais do magistério; programas de apoio a projetos educacionais e de pesquisa propostos por instituições e por profissionais do magistério das escolas públicas que contribuam para sua formação continuada e para a melhoria da escola e, ainda, programas que promovam a articulação das ações de formação continuada com espaços de educação não-formal e com outras iniciativas educacionais e culturais. Como não há clareza sobre o que são novos desenhos curriculares, é possível supor que o pragmatismo e a "epistemologia da prática" sejam os critérios valorizados. Igualmente, é provável que o rol de alternativas financiáveis promova uma corrida pela disputa dos vultuosos recursos alocados.

Os resultados da oferta de formação inicial e continuada decorrentes das ações do Decreto precisarão ser melhor estudados. Observando-se a oferta de formação inicial, por exemplo, é possível identificar que a prioridade às licenciaturas em Física, uma das que menos forma professores, em todo o Brasil, está longe de ser contemplada. Além disso, o número de licenciaturas na modalidade de EAD, em algumas UF, sinaliza mais uma vez a centralidade 
issn: 1808 - 799x

ano 8 - número 11 - 2010

conferida à essa modalidade como estruturante não só da formação continuada como da formação inicial. ${ }^{4}$

Entre o dito e o feito, até o momento, há algumas sinalizações sobre os efeitos concretos das propostas em disputa. É o caso da oferta padronizada de formação continuada, em 2009, restrita, na maioria das UF, a dois cursos, na modalidade a distância: Tecnologia na Educação: ensinando e aprendendo com as TICs e Introdução á Educação Digital, considerados, certamente, requisitos à entrada do trabalhador docente no "admirável mundo novo". Em 2010, segundo ano da política, além desses e, ainda, de forma padronizada, estão sendo oferecidos, com destaque, cursos de $250 \mathrm{~h}$, ou menos, voltados ao atendimento especializado aos portadores de necessidades especiais. Resgatar o sentido de uma formação continuada parece, por isso mesmo, ser prioridade.

Não há como dissociar a formação do trabalhador docente das suas condições de trabalho e carreira, o que faz do referido Decreto uma tentativa restrita de enfrentar a questão. $O$ fato de não serem resolvidas as demais faces do problema, isto é, a precarização das relações de trabalho docente, com destaque para a flexibilização de vínculos, a baixa remuneração, a ausência freqüente de concursos públicos e a expansão da contratação de temporários é revelador não só de um olhar superficial sobre o trabalho docente, tradição antiga das políticas da área, como da preservação das ações emergenciais. Os professores terão tempo para estudar? Serão liberados de suas turmas? Serão atendidos dentro das suas preferências ou terão que cursar o que "for possível"? As estratégias de formação continuada incluirão, de fato, o mestrado e o doutorado, ou apenas o mestrado profissional?

A formação que sonega ou distribui de forma desigual o conhecimento enfraquece o trabalhador docente e é compatível com o lugar ocupado pela educação pública no Brasil, em que pesem os veementes discursos sobre a importância de valorizar o magistério.

\footnotetext{
${ }^{4}$ Ver Plataforma Paulo Freire
} 


\section{frabalhonecessário \\ issn: 1808 - 799x \\ ano 8 - número 11 - 2010}

\section{Considerações finais}

Ao concluir esta breve reflexão sobre a política federal de formação do trabalhador docente, reiteramos que faz parte da lógica do capital a destruição da força de trabalho. A subsunção real, ao definir a lógica da produção como um todo, traz efeitos importantes para a vida e o trabalho do professor. Submetido às leis do mercado, o poder do seu trabalho tende a se enfraquecer, tornando-se limitado, sendo por vezes sua prática social alienada, subordinada à racionalidade do capital. Nessa perspectiva, não seria possível esperar que tal política rompesse com a lógica do capital no interesse dos trabalhadores docentes.

O Estado, historicamente a serviço dos interesses privados, conhece bem o poder do trabalho dos professores, uma das maiores categorias profissionais entre os servidores públicos, na dianteira de movimentos em busca de uma escola pública democrática. Conhece, igualmente, as possibilidades do processo formativo que, comprometido com o professor e a realidade concreta da escola brasileira, busque as raízes das questões a serem superadas.

Por tudo isso, compreendemos que as soluções propostas pela atual política de formação sejam parciais e compatíveis com a lógica do capital que se amplia, também, para a área de serviços. A formação do trabalhador docente, com base em cardápios de ofertas padronizadas e desenvolvida expressivamente

a distância, reitera soluções restritas adotadas anteriormente. É, mais uma vez, o velho que não quer sair de cena, sem que sejam enfrentadas todas as faces do problema.

A luta pela valorização do trabalhador docente tanto em termos de formação como de remuneração e carreira faz parte da luta pela educação democrática, pública, laica e gratuita para todos e não para poucos. Essa luta, vale lembrar, é da classe que trabalha, não apenas dos professores. 


\section{frabalhonecessário \\ issn: 1808 - 799x \\ ano 8 - número 11 - 2010}

\section{Referências Bibliográficas}

BRASIL. DECRETO N 6755, de 29 DE JANEIRO DE 2009. Institui a Política Nacional de Formação de Profissionais do Magistério da Educação Basica, Disciplina a Atuação da Coordenação de Aperfeiçoamento de Pessoal de Nivel Superior - Capes no Fomento a Programas de Formação Inicial e Continuada, e da Outras Providencias.

CHICO OLIVEIRA: ENTREVISTA. CARTA MAIOR. Redação 06/01/2009.

Disponível em:

[http://www.cartamaior.com.br/templates/materiaMostrar.cfm?materia_id=15467] Acesso em: fevereiro de 2009.

DAMBISKI, Kátia. Trabalho e formação docentes: tendências no plano das políticas e da literatura especializada. Trabalho apresentado no GT - Trabalho e Educação- 29a Reunião da ANPEd .Caxambu, MG, outubro de 2006.

FREITAS, Helena. A (nova) política.de formação de professores: A prioridade postergada. Educ. Soc., Campinas, vol. 28, n. 100 - Especial, p. 1203-1230, out. 2007.

JAMESON, Fredric. Pós-Modernismo. A lógica cultural do capitalismo tardio. São Paulo: Editora Ática, 2002.

PROGRAMA DE PROMOÇÃO DA REFORMA EDUCATIVA NA AMĖRICA LATINA E CARIBE- PREAL. La remuneracion de los maestros en América Latina: ¿Es baja ¿ Afecta a calidade de la enseñanza? Claúdio de Moura Castro e Gustavo loschpe. PREAL: Janeiro de 2007.

SĖVE, Lucien. Começar pelos Fins - A nova questão comunista. The Marxists Internet Archive .Disponível em: http://www.marxists.org/archive/seve/index.htm Acesso: maio de 2008. 